\title{
Sudden cardiac death - what do we know and how do we prevent it?
} Nagły zgon sercowy - co wiemy i jak zapobiegamy?

\author{
Łukasz Zandecki ${ }^{1}$, Marcin Sadowski ${ }^{1}$, Szymon Domagała ${ }^{1}$, Agnieszka Łętek ${ }^{1}$, Marianna Janion ${ }^{1,2}$ \\ ${ }^{1}$ Il Clinic of Cardiology, Regional Polyclinical Hospital, Kielce Region Centre of Cardiology, Kielce, Poland \\ Head of Clinic: Prof. Marianna Janion MD, PhD \\ ${ }^{2}$ Department of Internal Diseases, Cardiology and Internal Medicine Nursing, Institute of Nursing and Maternity, Faculty of Health \\ Sciences, Jan Kochanowski University, Kielce, Poland \\ Head of Department: Prof. Marianna Janion MD, PhD
}

Studia Medyczne 2013; 29 (4): 328-337

Key words: sudden cardiac death, SCD, risk of SCD, prevention of SCD.

Słowa kluczowe: nagły zgon sercowy, SCD, ryzyko wystąpienia SCD, profilaktyka SCD.

\begin{abstract}
Sudden cardiac death (SCD) is an important clinical problem with a complex and multifactor background. Trends in its prevention have been dynamically developing over the last decades. Patients with ischemic heart disease, especially after myocardial infarction, represent the largest group at an elevated risk of SCD. Many congenital and hereditary diseases are associated with an increased risk of SCD, particularly among young people. Although far from perfect, left ventricular ejection fraction remains the only widely recognized, relatively objective and credible method of assessing the risk of SCD among patients with heart failure. Other methods for assessing the risk are waiting for the final confirmation of their usefulness in clinical trials. The implantable cardioverter-defibrillator (ICD) and its newer version - totally subcutaneous S-ICD - remain the most effective methods of SCD prevention. The only class of drugs with well-proven efficiency in most patients at risk of SCD is $\beta$-blockers.
\end{abstract}

\section{Streszczenie}

Nagły zgon sercowy (sudden cardiac death - SCD) stanowi istotny problem kliniczny o wieloczynnikowym podłożu. W ciągu ostatnich dekad dynamicznie rozwijają się trendy w zakresie zapobiegania SCD. Największą grupą pacjentów o podwyższonym ryzyku wystąpienia SCD są osoby z chorobą niedokrwienną serca, szczególnie po przebytym zawale serca. Wiele wrodzonych i dziedzicznych schorzeń wiąże się z podwyższonym ryzykiem wystąpienia SCD, przede wszystkim wśród osób młodych. U pacjentów z niewydolnością serca pomiar frakcji wyrzutowej lewej komory jest jedyną powszechnie uznaną, względnie obiektywną i wiarygodną, choć daleką od doskonałości, metodą oceny ryzyka SCD. Pozostałe metody wymagają ostatecznego potwierdzenia swojej przydatności w badaniach klinicznych. Najskuteczniejszą metodą profilaktyki jest wszczepialny kardiowerter-defibrylator (implantable cardioverter-defibrillator - ICD) oraz jego nowsza, całkowicie podskórna wersja S-ICD. Jedyną grupą leków o dobrze udowodnionej skuteczności znajdującą zastosowanie u większości chorych zagrożonych SCD są $\beta$-adrenolityki.

\section{Introduction}

Sudden cardiac death (SCD) is death caused by unexpected cardiac arrest, usually as a result of arrhythmia, which occurs within $1 \mathrm{~h}$ of the occurrence of the first symptoms.

It is estimated that as many as $40 \%$ of all cases of SCD may happen in the absence of witnesses. In such cases there are obvious difficulties with the classification of such deaths as sudden, using the $1 \mathrm{~h}$ criterion from the onset of symptoms to death. Some researchers propose the use of the criteria by the World Health Organization, which, according to the presence or absence of witnesses, allow the diagnosis of SCD to be made even up to $24 \mathrm{~h}$ after the moment when the deceased had been last seen, and nothing indicated that death would soon occur.

Sudden death should have a primary cardiac cause in order to be classified as SCD, no matter whether the patient had been previously diagnosed with a heart disease or SCD was its first manifestation. The majority of SCD take a course in the mechanism of primary arrhythmia leading to cardiac arrest. However, in the course of many acute states, including non-cardiologic, death is sometimes preceded by some form of arrhythmia. Deaths due to injury are easily excluded from the SCD group; however, certain classification difficulties are encountered concerning, e.g. pulmonary embolism, pneumothorax, cardiac tamponade, or fatal arrhythmias as a consequence of poisoning with pharmaceuticals or narcotics. 
In the light of these discrepancies it seems impossible to unequivocally define the phenomenon of SCD. In effect, various researchers adopt various definitions, which hinders the analysis of results of these studies. According to the adopted criteria, the percentage of SCD among all natural deaths is in the range $3.7-13 \%$, approximately $5.5 \%$ on average. When the 24-hour criterion is adopted, the percentage of SCD increases up to $18.5 \%$. On average, in the United States, SCD is responsible for 300,000-350,000 deaths annually (0.1-0.2\% population/year). In the group of patients with heart failure and ejection fraction (EF) $<30 \%$ it is the cause of approx. $20 \%$ of deaths annually, and in patients with ventricular tachycardia/ventricular fibrillation (VT/VF) in the late phase of myocardial infarction as much as 35\%. It seems that in Europe the statistics are similar $[1,2]$. In the total population, ischemic heart disease (IHD) is the most frequent cause leading to SCD; therefore, the incidence of SCD is higher, the higher the incidence of IHD in a given population - the highest in the developed countries of Europe and North America. For the same reason, SCD more frequently occurs in males, and its incidence increases with age. It is estimated that IHD underlies over $80 \%$ of SCD. With increasingly more effective treatment of patients suffering from IHD and heart failure, the life span of these patients is prolonged, which also results in an increase in the incidence of SCD [3].

\section{Expansion of the problem}

\section{Pathophysiology}

The mechanisms of the development of arrhythmia leading to SCD are a complex phenomenon. Apart from the genetic conditioning and abnormal function of ion channels and cellular membranes resulting in disorganization of electrical potentials across the cell membrane, the most frequent cause is sudden or chronic ischemia, which leads to cell dysfunction or death. Also, macroscopic changes in the heart which favor the development of pathological pathways of electrical impulse conduction, such as myocardial scarring, fibrosis, and asymmetric hypertrophy, play an important role in the pathophysiology of SCD.

The conditions triggering arrhythmia may be: an acute ischemic episode, reperfusion, release of catecholamines, water-electrolyte imbalance, toxins, drugs, as well as a shift in autonomic balance towards the parasympathetic system (sleep, leisure). From among SCD mechanisms observed, ventricular tachycardia is most frequently the first documented arrhythmia (7-10\% of all SCDs), as well as catecholaminergic polymorphic ventricular tachycardia and tachycardia of 'torsade de pointes' type leading to ventricular fibrillation (65-85\% of all SCDs). Primary arrhythmias in patients with advanced heart failure and in old age are bradyarrhythmias and pulseless electrical activity (PEA), pre- viously called electromechanical dissociation, which constitute $20-30 \%$ of all SCDs. Among patients with implanted ICD, caused by PEA occurring after the discharge, 20-35\% die due to cardiac arrhythmia [4]. Asystole is sometimes the first rhythm observed in patients who die from the mechanism underlying SCD, whereas, in practice, all arrhythmias may ultimately degenerate into asystole [5].

Sudden cardiac death is an especially dramatic and unexpected event in young people, who often enjoy good health, as well as among sportsmen. In populations of young people SCD is statistically a more rare phenomenon, and its causes are more varied. In individuals aged under 35, IHD is the cause of only approximately $24 \%$ of cases of SCD. More frequently, the cause cannot be found or this is primarily arrhythmogenic heart disease, most often in the form of hereditary channelopathy (31\%). The remaining causes are hypertrophic cardiomyopathy or another form of hypertrophy of left ventricular hypertrophy, myocarditis, as well as congenital defects of the heart and coronary arteries [6].

\section{Cardiomyopathies}

Cardiomyopathies of non-ischemic etiology are a large group of disorders associated with an elevated risk of SCD. Hypertrophic cardiomyopathy (HCM) and arrhythmogenic right ventricular cardiomyopathy/ dysplasia (ARVC, ARVD) deserve special attention [7].

Recent studies show that the total risk of death due to hypertrophic cardiomyopathy is relatively low - lower than $1 \%$ annually. Past episode of VT/VF is the strongest single SCD risk factor in patients with HCM. The remaining major factors affecting risk are: extreme left ventricular hypertrophy $(>30 \mathrm{~mm})$, positive family history of SCD, synopses of unexplained etiology, and abnormal response of arterial blood pressure to physical effort [5].

In arrhythmogenic right ventricular cardiomyopathy/dysplasia, the heart muscle of the right ventricle is replaced by fat and fibrous tissue. Among abnormalities observed in ECG, most often QRS widening is observed (QRS $\geq 110 \mathrm{~ms}$ ) and epsilon wave on the descending branch of QRS complex in leads V1-V3. In addition, negative $\mathrm{T}$ waves are relatively often observed in these leads, or block of the right bundle of His (RBBB). In ECG, there occur additional ventricular beats, and in a computer averaged examination the presence of late potentials is observed. In imaging tests a considerable enlargement and impairment of contractility of the right ventricle is noteworthy, with slight changes in the left ventricle [5-8].

\section{Congenital anomalies of the coronary arteries}

Congenital anomalies of the coronary arteries are a rare and well-documented anomaly predisposing to 
SCD, especially in children and young adults. Potentially, the most important clinical consequences are associated with anomalies consisting in an abnormal branch of one of the coronary arteries. The frequency of the right coronary artery branch arising from the left sinus of Valsalva was estimated to be $0.92 \%$, while the left coronary artery arising from the right sinus of Valsalva was estimated to be $0.15 \%$, which means that more than $1 \%$ of the total population may be carriers of this potentially lethal defect [9]. In autopsy examination carried out among soldiers drafted into the US Army who died suddenly of a non-injury mechanism (126 cases within 25 years) it was found that congenital anomalies of the coronary arteries were the most frequently identified cause of deaths (21 cases). In all cases the anomaly consisted in the left coronary artery arising from the left sinus of Valsalva, and its further course between the aorta and pulmonary artery. In addition, in single cases spontaneous dissections, aneurysm and hypoplasia of coronary arteries were described [10].

The consequence of abnormal arising of the coronary artery is an impairment of the effective coronary flow, usually due to the slit-like orifice of the abnormal artery, the sharp angle of the orifice, and deformation of the section of artery taking its course in the aortic wall during the period of elevated arterial pressure. Abnormal orifices of the coronary arteries may be presented by means of imaging examinations, including echocardiography. There are several surgical techniques for correction of anomalies of the coronary arteries; however, they are practically reserved only for symptomatic patients or those with documented ischemia of the heart muscle - class I disorders. Considering the considerable risk of SCD, surgical intervention should also be taken into account (class IIa) in all patients with diagnosis of the left coronary artery arising from the right sinus of Valsalva, and takes a further course between the aorta and pulmonary artery [11].

\section{Brugada syndrome}

In 1992, the brothers Pedro and Josep Brugada published a report in which they described 8 patients without any apparent organic heart disease, with recurrent sudden cardiac arrests (SCA). Considering changes in the ECG recording observed in all the patients described, which resembled right branch bundle block, with persistent ST segment elevations in leads V1-V3, the researchers proposed distinguishing a new nosologic unit from among idiopathic VF [12] Soon after, reports were published concerning new cases of this disease, which was called the Brugada syndrome (BS).

Changes in ECG typical of the BS may take the form of three patterns defined as types 1,2 and 3. Type 1 changes are cove-shaped ST segment elevations with at least $2 \mathrm{~mm}$ passing across the negative $\mathrm{T}$ wa- ves in at least 2 precordial leads from among V1-V3. Such a recording may resemble the right branch bundle block (RBBB); however, the remaining diagnostic criteria of RBBB concerning S wave in leads I and V6 are not satisfied. In addition, in RBBB, the course of the descending branch is typically directed sharply downwards to the basic line, and in the BS it is rather like a concave bow, or takes a skew course directly towards the descending branch of the negative $\mathrm{T}$ wave. Type 1 changes in ECG may occur spontaneously, but may also be observed only after the performance of a provocation test with a sodium channel blocker (e.g. ajmaline). In both cases, the presence of these changes is equally important in the context of making a diagnosis; however, spontaneous changes are associated with less favorable diagnosis and different recommendations concerning the prophylaxis of SCD [13, 14].

The latest studies suggest that changes in lead V3 are not diagnostic for BS, and the typical changes in only one lead from among V1-V2 are associated with the same clinical characteristics and risk of arrhythmia as in patients with BS diagnosed based on the current criteria [15].

The sole presence of changes in ECG is insufficient for making the diagnosis of BS. Changes in ECG characteristic of BS may be observed in patients with electrolytic disorders, who take certain drugs (e.g. amitriptyline, $\beta$-blockers), those poisoned with alcohol or cocaine, patients several hours after electrical cardioversion, and in many other cases, which should be excluded before making the diagnosis of BS. In order to diagnose BS, together with changes in ECG of type 1 pattern (or without provocation with a sodium channel blocker, in at least 2 leads from among V1-V3), at least one of the following criteria should be satisfied: - documented ventricular fibrillation (VF),

- documented polymorphic ventricular tachycardia (VT),

- a family history of sudden cardiac death at $<45$ years old,

- coved-type ECGs in family members,

- inducibility of VT with programmed electrical stimulation,

- syncope,

- nocturnal agonal respiration [13].

On the molecular level, the essence of the disease is imbalance between ionic currents occurring during the first phase of the functional potential in the subepicardial layer of the right ventricle muscle. The sodium channel defect, and related to it mutation of the gene SCN5A, present in $18-30 \%$ of patients with BS, is best documented. To date, more than 100 other mutations have been described as being responsible for BS. These mutations are manifested by defects in the expression of sodium channel elements or particles affecting their function which, in consequence, leads to delay in the inward sodium current. The mutations 
described also concern other channels, potassium and calcium, the dysfunction of which consists in the intensification of the outward ionic current, which disrupts the above-mentioned balance between the ionic currents during the first phase of the functional potential.

The BS is a disease on a genetic background, inherited in an autosomal dominant way; however, as many as $60 \%$ of cases are spontaneous, without apparent genetic history [16].

\section{Long QT syndrome}

Long QT syndrome (LQTS) is a genetically conditioned disease of the ionic channels, associated with an increased risk of occurrence of catecholaminergic polymorphic ventricular tachycardia of torsade do pointes type (TdP) and, in consequence, SCD. Twelve types of LQTS have been identified, conditioned by over 500 mutations. Most frequently there occur mutations at the LQT1 locus (mutation of the sub-unit of the sodium channel, $43 \%$ of cases) and LQT2 (mutation of the sub-unit of the potassium channel, $45 \%$ of cases), slightly more rarely LQT3 (mutation of the subunit of the sodium channel, $7 \%$ of cases); the remainder are very rarely encountered [8]. The risk of cardiac events is considerably higher in patients with mutations LQT1 and LQT2, but in patients with mutation at the LQT3 locus, events ending in death occur more often; therefore, the total mortality is similar, irrespective of genotype [17].

The agents triggering TdP may be, according to the type of mutation: physical effort (LQT1), psychological stress (LQT2), or, in contrast, leisure (LQT3). Congenital LQTS is the cause of 3,000-4,000 SCDs annually among children in the USA. It is estimated that incidence of this disease is 1 per 7,000-10,000 total population [5]. Patients with QT interval $>500 \mathrm{~ms}$ are especially exposed to the occurrence of dangerous arrhythmias.

In the pharmacological treatment of LQTS, $\beta$-blockers are applied, although their effectiveness in patients with LQT3 is doubtful. According to the ESC recommendations of 2006, in secondary prevention in patients who had undergone SCA, ICD implantation is recommended. It should be considered in patients with VT or syncope, despite the use of $\beta$-blockers, or surgical treatment may possibly be considered in the form of resection of the left cervical-thoracic sympathetic ganglia as a supplementary method [2].

Apart from the congenital form, the prolongation of the QT interval may be the effect of electrolytic disorders or drugs consumed by a patient. Hypokalemia and hypomagnesemia diagnosed in the serum lead to intracellular deficit of these ions, prolonged repolarization and risk of dangerous arrhythmias. Hypocalcemia and hypothermia also prolong the QT interval, but are rarely the cause of arrhythmia [5].
Drugs prolonging QT interval include, among others, amiodarone, azithromycin, quinidine, chlorpromazine, citalopram, erythromycin, flecainide, haloperidol, clarithromycin, methadone, moxifloxacin, procainamide, sevoflurane, and sotalol.

In the age groups 15-50, longer QT intervals are observed in females than in males. This is probably due to the shortening of the QT interval as a result of the effect of male sex hormones, and not the QT prolongation during the reproductive period in females [18].

The domination of females among patients with congenital long QT syndrome, observed already in the 1970s, remains unclear. The LQTS inheritance pattern is not typical of a gender-related disease, and does not explain the unequal distribution of the incidence of this disease among males and females. The sole fact that in all females relatively long QT intervals are observed, while the diagnostic criteria of LQTS do not consider the differences between genders, may cause a systematic error and favor the diagnosis of this nosologic unit in females. Nevertheless, analysis of data from the register of patients with congenital long QT syndrome suggested the conclusion that the risk of the first cardiovascular event in these patients (syncope, SCA SCD) is higher in males aged under 15, but among females aged 15-40 this risk is significantly higher [19].

\section{Other causes}

Very rarely the short QT syndrome $(<300-$ $350 \mathrm{~ms}$ ), which is also associated with the family occurrence of heart rate disorders or sudden cardiac deaths, may be the cause of SCD. In 70\% of patients with this syndrome, concomitant atrial fibrillation is observed. Quinidine and propafenone, which cause QT prolongation to the normal values and decrease the frequency of the attacks of atrial fibrillation, prove to be pharmacologically effective. Also ICD implantation is applied in the prophylaxis of SCD [8].

Dangerous ventricular arrhythmias may sporadically occur also in patients with Wolf-ParkisonWhite syndrome (WPW), in the situation when the concomitant atrial fluttering or fibrillation is conducted via an additional pathway inducing a rapid ventricular response, which may degenerate into VF. In this special case, the treatment is causative and consists in the ablation of the additional pathway.

In addition, a higher risk of SCD was described in patients with congenital defects (e.g. tetralogy of Fallot, transposition of the great artery) and acquired (e.g. aortic stenosis), as well as inflammatory states and metabolic diseases (e.g. amyloidosis) taking a course affecting the heart. Among patients with chronic renal disease during the period of dialysis therapy, SCD is the most frequent mechanism of death (27-29\%). In this group of patients, the annual mortality due to 
SCD is $60 / 1000$ patients/year (in the total population $1.89 / 1000$ person/year) [20].

\section{Early repolarization syndrome}

Early repolarization syndromes (ERS, ER) feature an electrocardiographic symptom consisting in the elevation of the point where the QRS complex connects the ST segment (so-called J-point) in at least two adjacent leads, at least $0.1 \mathrm{mV}$ from the isoelectric line. However, the elevation of the J-point may be of a character of notching of the final segment of the QRS complex or deformation, described in English language literature as slurring (there is no accepted Polish equivalent) [21]. These changes have been described since the 1930s, and for the first time were called ER in 1951. While evaluating the ECG recording, changes typical of ERS are morphologically defined as J wave (late delta wave, Osborn wave) and are the result of the non-heterogeneous course of repolarization within the heart muscle. Disorders of this type occur in certain known diseases, such as BS or ARVC, where changes are observed resembling a J wave in leads V1-V3. In practice, it is sometimes difficult to unequivocally assess whether we are dealing with non-characteristic RBBB, BS, epsilon wave or $\mathrm{J}$ wave; therefore, evaluation from the aspect of ERS practically does not concern leads V1-V3 (however, in these leads one may describe an epsilon wave, RBBB or changes typical of BS).

Until recently, ERS in the remaining leads were considered as standard variants. During the period 2008-2009, three reports were published suggesting a relationship between ER in leads above the bottom and lateral wall with SCD [22-24]. It was also observed that the faster the cardiac function, the more clear the ECG changes, and the higher the risk of arrhythmia. The ERS may, in a sense, explain the occurrence of VF, to date defined as idiopathic.

At present, the data available is too scarce to reliably evaluate the risk of SCD and specify the standards of procedures in patients with ERS. In asymptomatic patients with ERS in ECG, without positive family history, neither further diagnostics nor SCD prevention are necessary - especially considering that ERS in males is very frequently observed: in Europe in $89 \%$ of sportsmen practicing endurance disciplines, and in $36 \%$ of the control group, mainly of sedentary style of life during the day [25].

\section{Sudden cardiac death}

The most effective form of SCD prevention is the use of implantable converter-defibrillators (ICD). Each time, indications for the use of such a type of appliance should be comprehensively analyzed, because they are not free from potential undesirable effects, including serious, life-threatening complications.
Their effect on life comfort should also be taken into account, and patients should be reliably informed not only concerning benefits, but also about possible inconveniences related to the use of the appliance [26].

There appear voices of criticism that the current recommendations in the area of indications for ICD implantation cause unnecessary overuse of these devices. It cannot be excluded that anti-arrhythmic drugs, especially $\beta$-blockers, show a similar effectiveness in some groups of patients qualified for ICD transplant. The comprehensive study AVID, which compared the effectiveness of pharmacological treatment and ICD in secondary prevention, was prematurely interrupted due to significantly higher mortality in the group without ICD. Nevertheless, some aspects of this study evoke doubts, whether comparing ICD and therapy with $\beta$-blocker, the results would thus clearly speak on behalf of ICD in all groups of patients [1]. Moreover, benefits from the use of ICD in the elderly and in females have not been unequivocally confirmed to date.

In all comprehensive studies (AVID, MADIT I, MADIT II, MUSTT, SCD-HcFT, DEFINITE), based on which recommendations were formulated concerning the use of ICD in patients at risk of SCD, females constituted a decisive minority (8-29\%), while the conclusions were drawn for both genders jointly. In the study SCD-HeFT conducted in a group of females who were implanted with ICD, no significant reduction in mortality was observed, compared to the control group (HR $0.96,95 \%$ CI $0.58-1.61$ ), partly due to the fact that among females SCD constituted the lowest percentage of all deaths.

At the present stage of studies, in the prevention of SCD in females, criteria are applied which are currently the same for males, although the benefits in the group of females have not been sufficiently documented [27]. The precondition for undertaking a decision concerning ICD implantation is that the patients qualified for the procedure had the chance to live for at least one year in good general state [2]. From the aspect of pharmacoeconomics, considering the current process of these devices, it would be cost-effective to apply ICD exclusively in patients at high risk with anticipated life expectancy $>10$ years [1].

Alternatives for 'traditional' ICD are S-ICD devices (subcutaneous-ICD), the greatest advantage of which is the lack of complications associated with endocavitary electrodes. The S-ICD evokes especially great interest from the aspect of young people with indications for the implantation of a defibrillator, and in patients in whom the traditional transvascular access is hindered or impossible.

Observations to date suggest that the effectiveness of discharges and detection of arrhythmia by S-ICD is comparable with traditional ICD; however, for an effective discharge, higher energy is necessary, which 
may cause more painful discharges, create a higher risk for others and reduce the life of the battery. The S-ICD functions only as a cardioverter-defibrillator, without the function of a cardiostimulator. Therefore, it does not enable stimulation of the heart in any other form than a high-energy discharge, and is capable of neither stimulating excitations in the case of bradyarrhythmia, nor a series of rapid excitations applied in ventricular tachycardia (ATP); it also does not allow resynchronization therapy (CRT) [28]. The long-term effectiveness and quality of life of patients with S-ICD will be evaluated by the recently initiated register EFFORTLESS S-ICD, in which approximately 50 centers from Europe and New Zealand participate [29].

\section{Evaluation of sudden cardiac death risk}

The decision concerning ICD implantation is preceded by family history taking and clinical assessment considering the history of symptoms (presence of syncopes), documentation of arrhythmia (past VT and VF episodes), evaluation of the left ventricle systolic function, result of electrophysiological examination, and sometimes also other characteristics typical of an individual nosologic unit. Among patients with post-infarction impairment and heart failure, prior to making a decision concerning ICD implantation, an assessment of the functional class according to NYHA and left ventricular ejection fraction (LVEF) are of decisive importance. Although at present this is a commonly accepted and applied method for the qualification of patients, relatively commonly there occur doubts whether it is sufficient from the aspects of both its sensitivity and specificity in qualifying patients at the highest risk of SCD.

The application of the LVEF evaluation for the stratification of risk of SCD is based on the assumption that damaged, contraction inactive cells of the heart muscle and past-infarction scars may be a starting point of lethal arrhythmia; the larger the area they occupy, the higher is the risk of initiation and persistence of arrhythmia. The LVEF evaluation is an indirect assessment burdened with measurement error related to the method applied and person performing the examination. Usually the range of measurement error should not exceed several percent; however, in the case of patients with EF within the range 30-35\%, this several percent may be of decisive importance. As a result, the same patient may be qualified for ICD implantation or not, irrespective of the fact who performed the examination and what method was used for calculating LVEF. Critics also argue that EF evaluation is neither a sensitive method (as many as $2 / 3$ of SCD occur in patients with LVEF > 35\%) nor a specific method (it is necessary to implant as many as 11 ICD to save one life within 3 years) [30]. Among females, the situation is still less favorable - as many as $50 \%$ more females than males who experienced SCA did not have sig- nificantly decreased LVEF $(<35 \%$ ) [31]. According to the analyzed study and the time window in which the assessment is performed, the statistics of specificity may change even up to three or four implanted ICD in order to save one life within 5 years, which is a considerably better result than any other form of pharmacotherapy, even considering the higher costs of application of ICD [32].

At present, new non-invasive methods are being sought for the assessment of SCD risk. The majority of these methods are based on electrocardiography. The ECG enables evaluation of heart muscle impairment based on changes in its electrical activity. Repolarization is the period of functional potential most sensitive to possible disorders of the electrical activity. Out of the entire period of repolarization, it is relatively easy to detect changes in the ST segment, because in a correct electrocardiogram the ST segment usually takes a course along the isoelectric line. This means that in normal conditions, during repolarization, there occur changes in the transmembrane potentials in the cells of the heart muscle. However, different from the TP segment, which is the marker of the isoelectric line, the lack of changes of potentials during the ST segment is not the effect of a static balance, but results from the continuous, dynamic activity of many ionic channels and the flow of inward and outward ionic currents in cells, the function of which is coordinated in a way that, despite constant exchange of ions between heart muscle cells and the surroundings, for several hundred milliseconds these currents are balanced, and changes of transmembrane potentials do not occur. Only the closure of inward-cell calcium current and increase in outward cell potassium current result in the violation of this balance and decrease in the value of the potential to which the $\mathrm{T}$ wave is equivalent in the ECG.

The second search area is that of disorders in the normal response of the sinus node expressed by the adaptation of the cardiac rhythm frequency to the regulatory effect of the autonomous system. In this case, due to the necessity for analysis of the sinus rhythm, these methods are not applicable in a relatively large group of patients with persistent atrial fibrillation.

\section{QT dispersion}

Dispersion of the QT interval (QTd) is defined as the difference between the longest and the shortest QT interval in a standard 12-lead ECG, expressed in milliseconds. In healthy individuals, this is 30-60 ms. QTd describes heterogeneity (dispersion) of repolarization between various parts of the heart muscle.

Many researchers describe the relationship between the QT dispersion of 60-80 ms and heart muscle ischemia, and an increased risk of death due to cardiovascular causes. On this basis, a hypothesis was posed that QTd may be the symptom of discrete dis- 
orders of the repolarization period and may be associated with an increased risk of SCD, especially if QTd $>80 \mathrm{~ms}$. However, the results of studies of the usefulness of QTd in this respect are divergent. The QTd may be measured manually or, more precisely, by computer, although irrespective of the method there are usually difficulties in precise measurement related primarily to the determination of the end of the $\mathrm{T}$ wave. These difficulties in association with the observed daily variability of QTd and lack of universal standards for this method burden it with a high risk of error. In fact, some researchers question the existence of QT dispersion at all, and consider the differences observed during QT intervals as artefacts resulting from imprecision of the measurement method and differences in the specificity of uni- and bipolar leads. On the other hand, relatively many studies have confirmed the idea of QT dispersion and its role as a risk factor of SCD. Nevertheless, due to difficulties with precise measurement of the QT interval and lack of uniform standards for this method, the predictive value and clinical usefulness of QTd require further verification. Apart from QTd, a twin parameter, QTcd, is being examined, i.e. cardiac rhythm frequency corrected QTd. To date none of them has shown a clear domination over the other in the context of predicting cardiovascular events [33, 34].

\section{T wave alternans}

The phenomenon described as $\mathrm{T}$ wave alternans (TWA) concerns the alternate occurrence of two morphologically different $\mathrm{T}$ waves. $\mathrm{T}$ wave alternans was observed as early as in 1909 and from the beginning it was associated with unfavorable prognosis. An interest in this method returned as late as in the 1980s, together with the development of computer techniques which enabled the recording of microvolt TWA, visible only after amplification of the ECG signal and analysis with the use of special algorithms. The registration of highly amplified ECG is usually performed from the system of corrected orthogonal Frank leads.

$\mathrm{T}$ wave alternans may be permanent or transitory. In patients after myocardial infarction, TWA may occur as late as after several weeks or months, considerably more rarely disappearing after this time. $\mathrm{T}$ wave alternans may also reveal itself only during the acceleration of cardiac rhythm; therefore, the protocol of TWA examination covers the recording of ECG during exercise cardiac stress test [35]. The presence of TWA correlates with a higher risk of SCD, but an opposite relationship is better documented - the lack of TWA in a patient who had suffered myocardial infarction with considerably lowered LVEF is associated with a significantly lower risk of SCD. Indirect evidence for a high negative prognostic value was provided, among others, by a study in which it was observed that if the strategy of TWA evaluation was applied prior to making a decision concerning ICD implantation (according to the criteria of the MADIT-II study), instead of 18 implanted devices needed to save one life, it would be enough to apply seven (during the mean 20-month period of follow-up) [36].

European ESC guidelines recommend paying attention to alternations of $\mathrm{T}$ wave (class I) during the assessment of ambulatory ECG. In addition, according to the ESC guidelines it is justifiable to apply analysis of alternations of $\mathrm{T}$ wave for the improvement of validity of diagnosis and assessment of the risk in a group of patients with life-threatening ventricular rhythm disorders (recommendations class IIa) [2].

\section{Late potentials}

Signal averaged electrocardiogram (SA-ECG) allows analysis of late potentials (LP), which are low-voltage oscillations at the ends of QRS complexes, as a result of free and non-heterogeneous conduction. The anatomic substrate for this type of change is most frequently post-infarction scars; however, similar disorders have also been observed in the course of other diseases - in cardiomyopathy, myocarditis, and diseases taking course with the infiltration of the heart muscle.

The majority of studies of LP in patients after myocardial infarction (MI) were conducted even before the age of reperfusion and early invasive strategies in the treatment of MI. It was observed that LP may occur as early as several hours after infarction, and their frequency increases up to day 7-10 after MI. Usually, if LP do not appear at the discharge of a patient from hospital, they rarely occurred later. A high negative predictive value of LP was documented in predicting arrhythmia events, but simultaneously attention was paid to the positive predictive value of this method. The limitation of the method remains the parameters of ECG signal filtration subjected to computer analysis.

At present, the importance of LP seems to be rather small in patients after MI who had undergone primary transcutaneous coronary intervention, as well as in the remaining diseases associated with a higher risk of SCD. Exceptions are ARVC and selected primary channelopathies, especially the BS. In these disorders a clearly more frequent occurrence of LP is observed, and studies are continuing concerning the use of this method for the assessment of SCD risk in the course of these diseases [37].

\section{Variability and turbulence of heart rate}

During the last three decades, the relationship between autonomic system dysfunction and risk of sudden cardiac death has been relatively intensively examined. The effects of these studies are methods analyzing daily variability of heart rate, as a factor re- 
flecting regulatory efficacy of the autonomous system. Among these methods, the most promising are heart rate turbulence (HRT) and various forms of heart rate variability (HRV).

The precondition for undertaking HRT analysis is the presence of sinus rhythm and additional, single ventricular excitations. The majority of studies of HRT concerned patients after myocardial infarction, and this method is designed primarily for this group of patients. The idea of the method consists in the assessment of acceleration, and subsequently gradual deceleration of heart rate after every additional ventricular excitation. In patients with a high risk of SCD, such a reaction of heart rate to additional ventricular excitation is disturbing. Traditional analysis of Holter ECG recording does not enable the assessment of HRT. For this purpose, the recording is subjected to computer analysis, obtaining an averaged graph presenting variability of duration of R-R intervals directly after additional ventricular excitations [38]. From the graph, two parameters are read, considered as reflecting best the essence of HRT: turbulence onset (TO), and turbulence slope (TS). The TO $<0 \%$ and TS $>2.5 \mathrm{~ms} / \mathrm{RR}$ are considered as a standard [39].

Heart rate turbulence are produced as a result of baroreceptor reflexes after insufficiently effective hemodynamically additional ventricular excitation. The lack or weakening of HRT is associated with disorders in autonomous regulation of the function of the sinus node mediated by the vagus nerve [40]. Comprehensive retrospective and prospective studies confirmed that HRT assessment is a strong, independent death risk factor in patients after MI, and the usefulness of this technique was also confirmed in other groups of patients. It seems that at the present stage it is justifiable to carry out intervention studies in order to confirm clinical usefulness of HRT evaluation in the stratification of risk of SCD [39].

Heart rate variability describes the daily variability of the heart rate under the effect of activity of the autonomous system. The subjects for HRV analysis are temporary fluctuations in the duration of subsequent RR intervals as a effect of mechanisms regulating intrasystemic homeostasis. The methods of analysis cover tachogram, geometric analysis, time analysis, and the most advanced spectrum analysis. The analysis may be performed based on a short (5$15 \mathrm{~min}$ ) ECG recording conducted in controlled conditions provoking HRV (e.g. changes of body position). 24-hour ECG monitoring is more frequently performed, enabling the registration and assessment of the autonomous system response during normal daily activity. From among many parameters described, the most frequently assessed is SDNN (Standard deviation of all normal to normal $R-R(N N)$ intervals) [41]. The impairment of the sinus rhythm reflects disorders in the autonomous regulation of the function of the sinus node, and is the marker of SCD in class IIb according to ESC recommendations of 2006 [2].

From the computer processed recording of Holter ECG examination it is also possible to read other parameters describing the variability of heart rate. One of the forms of evaluation of the capacity of the autonomous system is the deceleration capacity (DC) parameter. DC concentrates on the potential capability of the heart rate for slowing down. There is evidence that the impairment of the function of the vagus nerve increases the risk of death, and from among the parameters describing daily variability of heart rate, deceleration capacity (DC) is best correlated with vagus nerve function. In patients after myocardial infarction with impaired deceleration capacity (DC $<2.5 \mathrm{~ms}$ ), the number of deaths is statistically higher than in patients with DC $>4.5 \mathrm{~ms}$, even despite the preserved ejection fraction [42].

The results of the study suggest the mutually supplementary character of HRT and DC. In patients after myocardial infarction, DC seems to be more rarely useful in the identification of patients with low death risk, while HRT effectively identifies patients burdened with a high risk. Therefore, it was proposed to analyze both parameters jointly. Abnormal HRT accompanied by abnormal DC was defined as severe autonomic failure (SAF). In patients after myocardial infarction with SAF and EF > 30\% the incidence of SCD (as well as total mortality) was comparable to the group with $\mathrm{EF}<30 \%$, and significantly higher statistically compared to patients without SAF. The application of both criteria jointly (SAF or EF $<30 \%$ ) allowed identification of half of patients at risk of death within 5 years [43]. Despite convincing evidence for the effectiveness of SAF in the identification of patients with the highest SCD risk, SCD from among patients after $\mathrm{MI}$ and $\mathrm{EF}>30 \%$, it should be emphasized that the conducted studies were only experimental observations, and clinical decisions were made based on generally adopted standard procedures in effect.

The final goal of clinical studies is to prove that a given method well identifies patients at the highest risk of SCD, and to discover whether patients will benefit from an individual medical intervention (e.g. CD implantation) made based on this method. In order to confirm this, comprehensive randomized intervention studies are necessary, while the currently conducted observation studies are a kind of pass justifying the rationality and ethical aspects of the intervention study. Successful results of such studies would not only establish their importance, but primarily would enable the precise determination of their clinical importance. There is much evidence that for a reliable assessment of SCD risk, based on which it will be possible to make decisions in clinical practice, several of the above-described methods will be jointly 
applied, which will be mutually supplementary and provide the fullest image possible.

\section{Summing up and conclusions}

Sudden cardiac death is a common phenomenon, especially in some populations of patients, from among which the largest group at risk of SCD are patients with the heart damaged in the course of ischemic disease. Other diseases increasing the risk of SCD are also associated with heart impairment, including at the molecular level, although sometimes this impairment is clinically asymptomatic, and SCD is the first symptom of the existing problem. Among diseases in the course of which an elevated risk of sudden cardiac death should be considered are various types of cardiomyopathy, congenital and acquired heart defects and defects of coronary arteries, end stage renal disease, inflammatory and metabolic diseases which affect the heart during their course, as well as a wide spectrum of genetically conditioned cardiac channelopathies.

By definition, SCD is an irreversible state; it is only possible to prevent it - reduce the risk of occurrence of lethal arrhythmias by the application of drugs and effectively treat cardiac arrest, which occurs directly prior to SCD. The most effective treatment is instant defibrillation. The time for performing this is very short; therefore, ICD are applied, which can additionally treat arrhythmias potentially leading to VF. The costs of treatment, as well as the possible complications and undesired actions related to their use, make necessary an optimum stratification of patients who actually require the application of ICD.

At present, the basic method for evaluation of the risk of SCD remains the assessment of the left ventricular ejection fraction interpreted together with clinical data. In the ESC recommendations of 2006, the evaluation of late potentials, variability and turbulence of heart rate were classified as class IIb with the level of evidence reliability $B$, while the assessment of TWA obtained recommendation class IIa, with the level of evidence reliability A. It was emphasized that these methods may be useful for the evaluation of risk and improvement of validity of diagnosis in patient with LVEF 30-35\%, as well as in patients with LVEF > 35\%. However, at the present stage, prophylactic actions should not be undertaken exclusively on their basis. There is no doubt that the above-described methods of evaluation of SCD risk will evolve. There will also appear new methods which will supplement the existing ones, or will be their alternative, and jointly will change the recommended standard procedures.

\section{References}

1. Katritsis DG, Josephson ME. Sudden cardiac death and implantable cardioverter defibrillators: two modern epidemics? Europace 2012; 14: 787-794.

2. Zipes DP, Camm AJ, Borggrefe $\mathrm{M}$ et al. ACC/AHA/ESC 2006 guidelines for management of patients with ventricular arrhythmias and the prevention of sudden cardiac death - executive summary: A report of the American College of Cardiology/American Heart Association Task Force and the European Societ. Eur Heart J 2006; 27: 20992140.

3. Chugh SS, Reinier K, Teodorescu C et al. Epidemiology of sudden cardiac death: clinical and research implications. Ther Ad Prog Cardiovasc Dis 2008; 51: 213-228.

4. Albert CM, Chae CU, Grodstein F et al. Prospective study of sudden cardiac death among women in the United States. Circulation 2003; 107: 2096-2101.

5. Aziz EF, Javed F, Pratap B et al. Strategies for the prevention and treatment of sudden cardiac death. Open Access Emerg Med 2010; 2010: 99-114.

6. Shephard R, Semsarian C. Advances in the prevention of sudden cardiac death in the young. Ther Adv Cardiovasc Dis 2009; 3: 145-155.

7. Christiaans I, van Engelen K, van Langen IM et al. Risk stratification for sudden cardiac death in hypertrophic cardiomyopathy: systematic review of clinical risk markers. Europace 2010; 12: 313-321.

8. Choroby wewnętrzne. Stan wiedzy na rok 2010. Szczeklik A (ed.). Medycyna Praktyczna, Kraków 2010.

9. Angelini P. Coronary artery anomalies: an entity in search of an identity. Circulation 2007; 115: 1296-1305.

10. Eckart RE, Scoville SL, Campbell CL et al. Sudden death in young adults: a 25-year review of autopsies in military recruits. Ann Intern Med 2004; 141: 829-834.

11. Frommelt PC. Congenital coronary artery abnormalities predisposing to sudden cardiac death. Pacing Clin Electrophysiol 2009; 32 Suppl. 2: S63-6.

12. Brugada P, Brugada J. Right bundle branch block, persistent ST segment elevation and sudden cardiac death: a distinct clinical and electrocardiographic syndrome. A multicenter report. J Am Coll Cardiol 1992; 20: 13911396.

13. Antzelevitch C, Brugada P, Borggrefe $M$ et al. Brugada syndrome: report of the second consensus conference: endorsed by the Heart Rhythm Society and the European Heart Rhythm Association. Circulation 2005; 111: 659670.

14. Kołodziej M, Śledź J, Janion M. Zespół Brugadów - niedoceniana przyczyna zgonów u osób bez organicznej choroby serca. Kardiol Pol 2009; 67: 157-161.

15. Richter S, Sarkozy A, Paparella G et al. Number of electrocardiogram leads displaying the diagnostic coved-type pattern in Brugada syndrome: a diagnostic consensus criterion to be revised. Eur Heart J 2010; 31: 1357-1364.

16. Brugada $P$, Benito $B$, Brugada $R$ et al. Brugada syndrome: update 2009. Hellenic J Cardiol 2009; 50: 352-372.

17. Zareba W, Moss AJ, Schwartz PJ et al. Influence of genotype on the clinical course of the long-QT syndrome. International Long-QT Syndrome Registry Research Group. N Engl J Med 1998; 339: 960-965.

18. Rautaharju PM, Zhou SH, Wong S et al. Sex differences in the evolution of the electrocardiographic QT interval with age. Can J Cardiol 1992; 8: 690-695. 
19. Locati EH, Zareba W, Moss AJ et al. Age- and sex-related differences in clinical manifestations in patients with congenital long-QT syndrome: findings from the International LQTS Registry. Circulation 1998; 97: 2237-2244.

20. Alpert MA. Sudden cardiac arrest and sudden cardiac death on dialysis: epidemiology, evaluation, treatment, and prevention. Hemodial Int 2011; 15 Suppl 1: S22-S29.

21. Budrejko S, Kozłowski D. Zespół wczesnej repolaryzacji - cichy zabójca? Kardiologia Oparta na Faktach 2010; 3: 280-286.

22. Haïssaguerre M, Derval N, Sacher F et al. Sudden cardiac arrest associated with early repolarization. N Engl J Med 2008; 358: 2016-2023.

23. Rosso R, Kogan E, Belhassen B et al. J-point elevation in survivors of primary ventricular fibrillation and matched control subjects: incidence and clinical significance. J Am Coll Cardiol 2008; 52: 1231-1238.

24. Tikkanen JT, Anttonen O, Junttila MJ et al. Long-term outcome associated with early repolarization on electrocardiography. N Engl J Med 2009; 361: 2529-2537.

25. Bianco M, Bria S, Gianfelici A et al. Does early repolarization in the athlete have analogies with the Brugada syndrome? Eur Heart J 2001; 22: 504-510.

26. Janion M, Sadowski M, Sielski J et al. Pierwotna i wtórna profilaktyka nagłej śmierci sercowej. Pol Arch Med Wewn 2006; 115, 67-74.

27. Curtis AB, Narasimha D. Arrhythmias in women. Clin Cardiol 2012; 35: 166-171.

28. Cappato R, Smith WM, Hood MA et al. Subcutaneous chronic implantable defibrillation systems in humans. J Interv Card Electrophysiol 2012; 34: 325-332.

29. Pedersen SS, Lambiase P, Boersma LV et al. Evaluation of factors impacting clinical outcome and cost effectiveness of the S-ICD: design and rationale of the EFFORTLESS S-ICD Registry. Pacing Clin Electrophysiol 2012; 35: 574 579

30. Zuern CS, Barthel P, Bauer A. Heart rate turbulence as risk-predictor after myocardial infarction. Front Physiol 2011; 2: 99

31. Chugh SS, Uy-Evanado A, Teodorescu C et al. Women have lower prevalence of structural heart disease as a precursor to sudden cardiac arrest: the Oregon Sudden Unexpected Death Study. J Am Coll Cardiol 2009; 54: 2006-2011.

32. Camm J, Klein H, Nisam S. The cost of implantable defibrillators: perceptions and reality. Eur Heart J 2007; 28: 392-397.

33. Bluzaite I, Brazdzionyte J, Zaliūnas R et al. QT dispersion and heart rate variability in sudden death risk stratification in patients with ischemic heart disease. Medicina (Kaunas) 2006; 42: 450-454

34. Somberg JC, Molnar J. Usefulness of QT dispersion as an electrocardiographically derived index. Am J Cardiol 2002; 89: 291-294.

35. Garcia Ede V. T-wave alternans: reviewing the clinical performance, understanding limitations, characterizing methodologies. Ann Noninvasiv Electrocardiol 2008; 13: 401-420.

36. Bloomfield DM, Steinman RC, Namerow PB et al. Microvolt T-wave alternans distinguishes between patients likely and patients not likely to benefit from implanted cardiac defibrillator therapy: a solution to the Multicenter Automatic Defibrillator Implantation Trial (MADIT) II conundrum. Circulation 2004; 110: 1885-1889.
37. Santangeli P, Infusino F, Sgueglia GA et al. Ventricular late potentials: a critical overview and current applications. J Electrocardiol 2008; 41: 318-324.

38. Schmidt G, Malik M, Barthel P. Heart-rate turbulence after ventricular premature beats as a predictor of mortality after acute myocardial infarction. Lancet 1999; 353: 13901396.

39. Bauer A, Malik M, Schmidt G et al. Heart rate turbulence: standards of measurement, physiological interpretation, and clinical use: International Society for Holter and Noninvasive Electrophysiology Consensus. J Am Coll Cardiol 2008; 52: 1353-1365.

40. Jurek S, Sredniawa B, Musialik-Łydka A et al. Heart rate turbulence - a new predictor of sudden cardiac death. Pol Merkur Lekarski 2000; 23: 55-59.

41. Kleiger RE, Stein PK, Bigger JT Jr. Heart rate variability: measurement and clinical utility. Ann Noninv Electrocardiol 2005; 10: 88-101.

42. Bauer A, Kantelhardt JW, Barthel P et al. Deceleration capacity of heart rate as a predictor of mortality after myocardial infarction: cohort study. Lancet 2006; 367: 16741681.

43. Bauer A, Barthel P, Schneider R et al. Improved Stratification of Autonomic Regulation for risk prediction in post-infarction patients with preserved left ventricular function (ISAR-Risk). Eur Heart J 2009; 30: 576-583.

\section{Address for correspondence:}

Łukasz Zandecki MD

II Clinic of Cardiology

Regional Polyclinical Hospital

Kielce Region Centre of Cardiology

ul. Grunwaldzka 45, 25-736 Kielce, Poland

Mobile: +48606 620729

E-mail: lukasz.zandecki@gmail.com 